\title{
Beyond social awkwardness: Problems with "reading" faces?
}

\author{
Janet Jankowiak, MD
}

Feelings of awkwardness at a party are not limited to the teenage scene. Remember the guy who won't look at you when he talks but mumbles as he gazes at his shoelace or the more unnerving fellow who gets too close and breathes into your face as he talks? Many people suffer from problems interacting with others. At the extreme, these people may be labeled with autism, Asperger disorder, and socioemotional processing disorders; see About Social Developmental Disorders on the next page. What makes social interactions so difficult for these people?

In a recent study, published in this issue of Neurology, Rebecca Hefter et al. ${ }^{1}$ suggest that problems with social interactions may be related to problems learning how to interpret faces. One of the ways we judge a person's emotional state is by "reading" his/her facial expression. During a conversation, "reading" your listener's expression helps you judge whether he/she understands or is interested in what you are saying. Without this ongoing assessment and modification of what you are saying, a conversation may become awkward, ineffective or worse.

Hefter's group suggests that people with social developmental disorders (SDD) have difficulties identifying faces and interpreting facial expression. To test this idea, they studied 26 adults with a number of different types of SDD. Information was obtained for each person regarding developmental history and emotional adjustment. Special attention was given to their use of eye contact, facial expression and gestures. Each person took a standardized intelligence test. Then, they took a special test to see if they recognized famous people. Pictures of 20 famous and 20 non-famous faces were shown to each subject. The task was to separate the pictures into groups of familiar and unfamiliar faces, and to name the familiar faces, if possible. Their re-

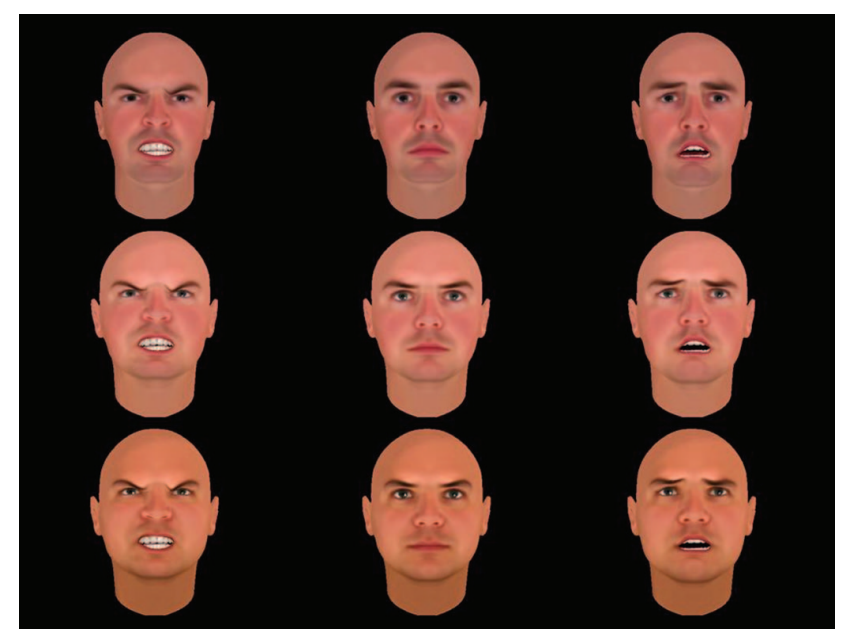

sponses were compared with those of 15 healthy people who served as a control group. To test the ability to recognize emotions, the study group was given other tests. In one test, they heard an audiotape of a woman's voice and were asked to interpret her tone of voice and emotional fluctuations of speech. In another, they were shown a videotape of a woman's face or body (from shoulders to thighs), and were asked to interpret what emotion she was showing. On a computer, the subjects were shown pictures of emotional faces and asked to describe them as happy, sad, angry or fearful. Another test was a type of "reading the mind in the eyes." The subjects were shown only photographs of pairs of eyes. They were given a choice of four complex emotional states to interpret for each pair of eyes: reflective, aghast (shocked), irritated, or impatient.

Ten of the 26 people with SDD scored well within the normal range on recognition of famous faces. However, within the whole group, there was a wide range of ability in interpreting facial expressions. This study showed that the ability to recognize a face was not related to the ability to interpret facial expressions. The 10 people with SDD who had normal recognition of facial identity had as much difficulty recognizing emotions as the 16 who had poor recognition of facial identity. Previous studies have also shown that people with autism or Asperger disorder have difficulty recognizing emotions both visually (facial expressions, gestures and body postures) as well as interpreting tone of voice and emotional changes of speech. Interestingly, Hefter's study showed that the ability to interpret a facial expression was correlated with the ability to interpret nonfacial emotional cues (for example, by voice and gestures or "body language").

From this study, Hefter's group suggested that the problems of "reading" facial expression in SDD might be linked to problems with interpreting emotions rather than problems with simply assessing faces. Without the ability to interpret the emotions of others normal social interactions are basically impossible. Further research is needed to better understand how and where in the brain various types of emotional cues are processed.

\section{Reference}

1. Hefter RL, Manoach DS, Barton JJS. Perception of facial expression and facial identity in subjects with social developmental disorders. Neurology 2005;65:1620-1625. 


\section{What are social \\ developmental disorders?}

Learning social skills and how to talk with others is something most people take for granted. By the time a child enters kindergarten, many of these basic skills are well established. Yet, it is clear that there is a very wide range of ability in these skills. Children who seem to have a knack for chatting comfortably with others become "popular" while those who are more awkward in groups often find themselves alone. Those at the "awkward" end of the spectrum run into the zone of social developmental disorders (SDD). The most severely impaired are labeled autistic. It has become clear that there are abnormalities in the brains of these children that do no develop as expected. Three of the SDDs are autism, Asperger disorder and socio-emotional processing disorder.

\section{What is autism?}

Autism is a disorder of the nervous system that affects the way a person communicates with others. Autistic disorders are considered to cover a wide spectrum; each individual is affected differently and to varying degrees. It is estimated that about 1.5 million Americans have some form of autism, or 1 in 166 births. Four times as many boys as girls are affected. It is generally apparent before the age of 3 . Both verbal and nonverbal (facial expression, gestures, body language) communication are affected. The severity of the disorder is quite variable, from mild social awkwardness to complete social isolation. Communication skills may be delayed or may never develop. Early signs in a small child may be minimal eye contact, a lack of social interest, and avoiding hugging and cuddling. These children may have difficulty interpreting the meaning of facial expressions (such as smiling or frowning) and gestures (such as winking). About half of children with autism may remain mute for their entire life. Others may show a great delay in learning to talk. These children often echo what people say to them without seeming to understand how to reply. Repetitive behaviors are common such as rocking, twirling their hair or waving their hands. These children may also be unusually sensitive to sounds that most people can completely ignore. For example, they may be so distracted by the sound of another person chewing gum that they cannot function. People with autism may also be obsessed about keeping routines and having objects in specific places. If an object is out of its expected place, the person may become outraged and overwhelmed by the change. Fortunately, many of these problems may improve with time, special education, and other therapies.

\section{What is Asperger disorder?}

Asperger disorder is thought to be a milder form of autism. Generally, these people have normal intelligence or may even be intellectually gifted. However, as in autism, they are socially inept and lack insight. They are inflexible to changes in expected routines and have a narrow range of interests. Often they develop in-depth knowledge about specific interests such as airplanes, trains, dinosaurs, etc. Repetitive behaviors, such as spinning objects, are also common. They may also be physically clumsy. However, unlike autism, as children they begin to speak on time. That is, by 2 years old they use single words and by age 3 they speak in phrases. Their spoken language often lacks emotional expression.

\section{What is socio-emotional processing disorder (SEPD)?}

This is a third type of social developmental disorder. In SEPD, language is learned at a normal time and the development of many thinking skills is normal. However, some types of thinking that are believed to rely on the nondominant side of the brain are abnormal. In a right-handed person, the left side of the brain governs verbal language and is called the dominant hemisphere. The right side of the brain is called the nondominant hemisphere. It has an important role in nonverbal communication, such as "reading" body language and interpreting emotions. In SEPD, testing on standardized intelligence tests (measures of IQ or intellectual quotient) shows a verbal IQ at least 10 points higher than nonverbal IQ. Normally, verbal and nonverbal IQs are about equal. This means that people with SEPD may have normal or even superior verbal skills, yet may still have a lot of trouble with social communication. Conversations may often be one sided. The person with SEPD may carry on a monologue on a favorite subject and not be aware of attempts of his/her listener to interject comments. At the same time, they most likely do not recognize the frustration or other emotional response their listener is showing. Consequently, it is difficult for them to develop emotional relationships, friendships, and even normal interactions with coworkers.

Although children with these disorders do not "outgrow" them, an early diagnosis is very important because specialized programs that can help are being developed.

\section{For more information}

Autism Society of America www.autism-society.org

National Institute of Child Health and Human Development www.nichd.nih.gov

American Academy of Child \& Adolescent Psychiatry www.aacap.org

Nonverbal Learning Disability Association

www.nldline.com

Asperger Syndrome Education Network

www.aspennj.org 


\section{Neurology}

\section{Beyond social awkwardness: Problems with "reading" faces? \\ Janet Jankowiak \\ Neurology 2005;65;E20-E21 \\ DOI 10.1212/01.wnl.0000189315.99934.fc}

This information is current as of November 21, 2005

Updated Information \& Services

References

Permissions \& Licensing

Reprints including high resolution figures, can be found at: http://n.neurology.org/content/65/10/E20.full

This article cites 1 articles, 1 of which you can access for free at: http://n.neurology.org/content/65/10/E20.full\#ref-list-1

Information about reproducing this article in parts (figures,tables) or in its entirety can be found online at:

http://www.neurology.org/about/about_the_journal\#permissions

Information about ordering reprints can be found online: http://n.neurology.org/subscribers/advertise

Neurology ${ }^{\circledR}$ is the official journal of the American Academy of Neurology. Published continuously since 1951, it is now a weekly with 48 issues per year. Copyright. All rights reserved. Print ISSN: 0028-3878. Online ISSN: 1526-632X.

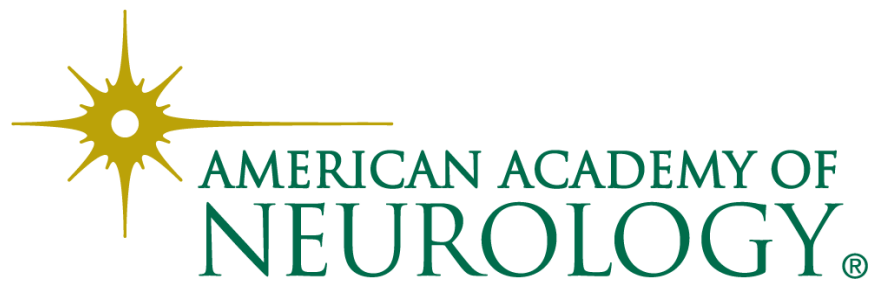

